\title{
Response of black currant plants to abnormalities in water and temperature regime 2020
}

\author{
Tatiana Zhidyokhina*, and Elena Tsukanova \\ Federal State Budgetary Scientific Institution «I.V. Michurin Federal Scientific Center», 393774 \\ Michurinsk, Russian Federation
}

\begin{abstract}
The water-temperature regime features in the Central Chernozem region in 2020 were reviewed. The main deviations from the mean perennial values of air temperature and humidity, as well as the precipitation distribution in spring and summer were determined. It was revealed that the distinctive feature of the entire 2020 growing season was significant instability of weather conditions - dry periods with high air temperatures were followed by wet and cool periods. In addition, a high amplitude of the daily air temperature difference was noted, which was significantly exceeding the average perennial values. The phenotypic, biological and physiological responses of black currant plants to anomalies of the water-temperature regime were studied; in particular, monitoring of photosynthetic activity dynamics of black currant plants revealed differences in response depth to damaging effects of adverse weather, depending on the variety and age of the plants. It was found that in black currant plants older than 5 years, the reaction to temperature anomalies is weaker than in three-year-old's. The reaction depth of phenological, biological and economic characteristics to the effect of water-temperature abnormalities firstly depends on the variety's genotypic features.
\end{abstract}

\section{Introduction}

There is no doubt that the cultivation territory's climatic conditions of any garden crop are one of the decisive factors that determine the completeness of the plant organism's biological potential realization [1-4]. At the same time, in our opinion, deviations of the territorial water-temperature regime have the most significant influence on the course of vital activity processes of cultivated plants. The analysis of temperature and precipitation over the last 90 years based on the data of Michurinsk agro-weather station allowed to reliably establish that the water-temperature regime in the middle horticulture zone has undergone significant changes, the main is the destabilization of both the temperature and water regime and regularly repeated alternation of periods with extreme values of meteorological indicators [5-7].

\footnotetext{
${ }^{*}$ Corresponding author: berrys-m@mail.ru
} 
One of the well-spread and popular shrubby berry crops in the middle horticulture zone is black currant. The plants possess a high level of ecological plasticity. New varieties are resistant to many climatic changes in recent decades, but even these plants often fail to realize their full biological potential due to negative impacts of meteorological anomalies... $[8,9]$.

In connection with the above-mentioned, the study of the black currant plants' reaction to the effect of water-temperature stressors and the establishment of varietal features of plants' ecological stability allows not only to identify the varieties' type most suitable for cultivation in the region, but also determines the actual vector of breeding studies.

The physiological state of perennial plants consists of a balance of positive and negative influences throughout their lives. The work of domestic and foreign scientists, as well as our research proved that one of the most accessible integral indicators that really reflect the response of plants' functional systems to stressors' exposure is the photosystems reaction of the chlorophyll-containing plant tissues, particularly photosystems 2 . In this regard, the ability to conduct non-invasive monitoring of photosystem 2 response in real time allows us to judge on the changes in the plants functional systems' condition and determine the depth of its reactions to stressor $[10,11,12]$.

\section{Materials and methods}

The meteorological data archives of the agro-weather station of the Central Black Earth region (FSBO "Tsentral'no-Chernozemnoe UGMS ") [13]. were used as actual meteorological information for the research territory; the following characteristics were used: dynamics of maximum and minimum air temperatures, daily temperature changes, daily precipitation, air humidity. These parameters in a generalized form characterize both therm al conditions and conditions of territory moistening.

Non-invasive contact monitoring of the plants' physiological state was carried out using "System of diagnostics of functional state of fruit and berry plants" [7, 12], based on fluorescence registration of chlorophyll "a" by the IFSP-2 device by the method Genty et al [11]. Fv/Fm indicator (ratio of maximum chlorophyll fluorescence to fluorescence variable) was used, characterizing the activity of the photosystem 2. The study of phenology, biological and economic indicators was carried out according to standard methods of varietal study $[14,15]$.

Research was carried out on Zelyonaya Dymka and Karmelita black currant varieties on plantations of FSSI "I.V. Michurin FSC". The age of plants was 3, 5 and 7 years.

\section{Results and discussion}

In this paper, we tried to establish the photo system reaction of leaves and various biometric indicators to the anomalies of the water-temperature regime of March-October 2020, to estimate the response depth in dependence on the biological characteristics of the variety and age of plants.

In general, the weather conditions of 2020 were significantly different from the average perennial ones. Already in March, abnormally high average daily air temperatures were observed $\left(6-13^{\circ} \mathrm{C}\right.$ above the average perennial values) and medium and low air humidity, with maximum temperatures reaching values of $+14.6 \ldots+17.6^{\circ} \mathrm{C}$ since March 8 and the average monthly air temperature exceeded the perennial average by $10.3^{\circ} \mathrm{C}$ with total precipitation more than 50\% lower than perennial averages (Fig. 1, 2). A significant negative effect on currant plants was caused by spring frosts of March 15-17 and 21-25 (the minimum air temperature reached... $-3,4 \ldots-6,8^{\circ} \mathrm{C}$ ). It should be noted that in the third 
decade precipitation was practically absent, and the air humidity fluctuated within $28-36 \%$ (at the norm of $84 \%$ for this period). All of the above had a significant impact on the development of black currant plants.

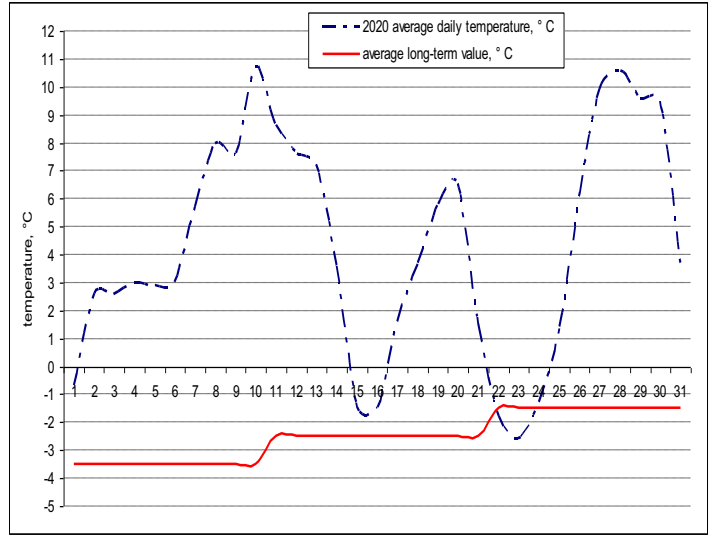

Fig. 1. Average daily air temperatures in March 2020 in comparison with perennial averages.

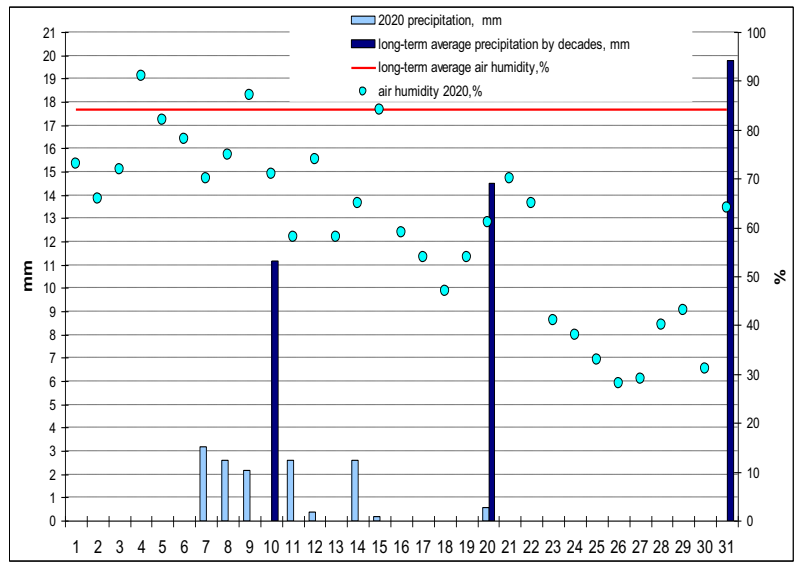

Fig. 2. Daily precipitation and air humidity in March 2020 in comparison with perennial averages.

The water-temperature regime of April and May was quite difficult for plants - in early April the minimum air temperature was... $-7.8 \ldots-3.4^{\circ} \mathrm{C}$. In total, 13 days with negative night-time air temperatures were observed in April, but the greatest negative effect on the black currant plants was caused by significant daily temperature differences (difference between day and night temperatures reached $14-18^{\circ} \mathrm{C}$ ), as well as alternation of warm (with an average daily air temperature of $+12-\ldots+15^{\circ} \mathrm{C}$ ) and cold (with a temperature of $+2 \ldots+4^{\circ} \mathrm{C}$ ) periods. A similar phenomenon was observed in May (Figure 3, 4). 


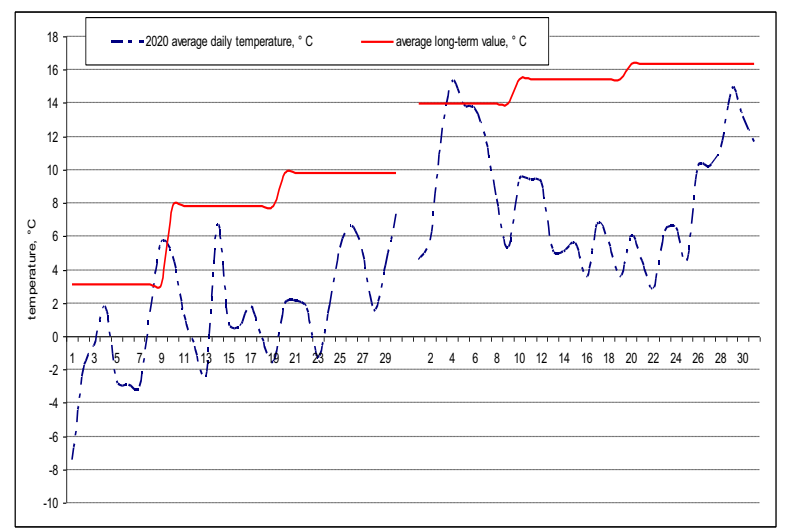

Fig. 3. Average daily air temperatures in April and May 2020 in comparison with perennial averages.

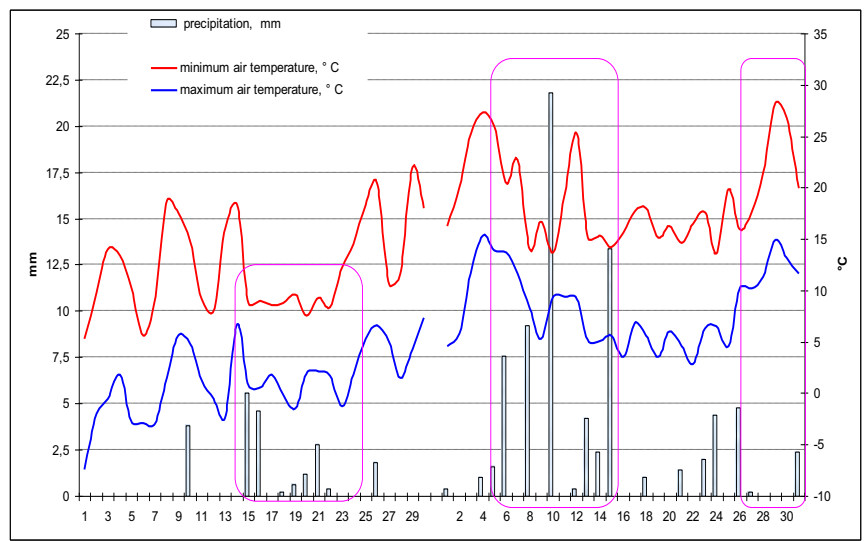

Fig. 4. Maximum and minimum air temperatures and precipitation in April and May 2020.

The above-mentioned weather conditions provoked very early start of black currant plants' vegetation and flowering, so the vegetation start of Karmelita variety occurred on March 10, the Zelyonaya Dymka variety - March 13. It should be borne in mind that the buds extension occurs in parallel with the leaves' growth, which is why the plants are most vulnerable during this period. At the same time, spring frosts in the second and especially third decade of March $\left(-6.8^{\circ} \mathrm{C}\right)$ led to significant damage to buds, because it is known that the air temperature below... $-5.0^{\circ} \mathrm{C}$ is critical for the crop during the buds isolation period $[9,16,17]$. (Figure 5).

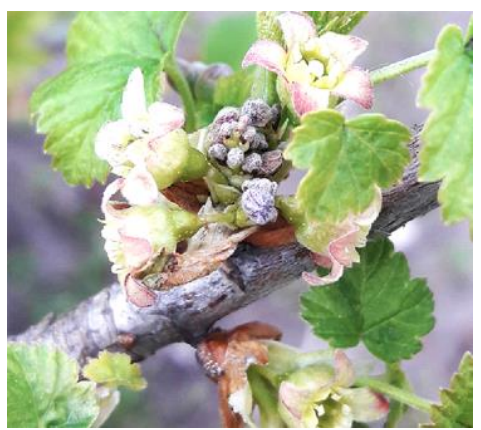

Fig. 5. The condition of plants after spring frosts. Karmelita variety. April 2020. 


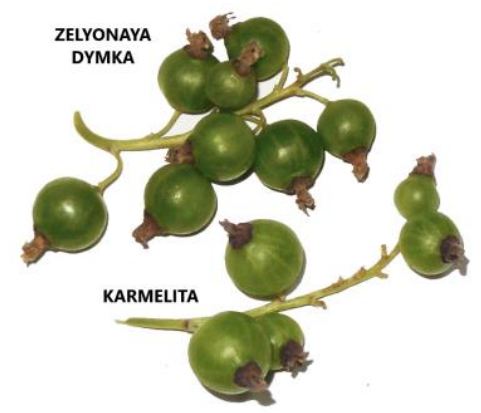

Fig. 6. The effect of spring frosts on the black currant fruit-setting, 2020.

Karmelita was the most severely affected variety- the maximum proportion of damaged buds was $57.8 \%$. A slightly later initiation of vegetation period in Zelyonaya Dymka variety provided it with a high level of buds preservation - the proportion of damaged buds did not exceed $1 \%$ (Fig. 5, 6).

An important value for the black currant yield is not only the percentage of damaged buds, but also the number of clusters with damaged buds. The assessment of the obtained experimental material showed that the proportion of clusters with spring frost damage in the Karmelita variety amounted to $72 \%$, whereas Zelyonaya Dymka was only $1.5 \%$. A reliable inverse correlation between the damage degree to clusters and buds and the timing of the vegetation start $(\mathrm{r}=-0,5 \ldots-0,6)$ and flowering $(-0.7)$ was established.

Low $\left(6-10^{\circ} \mathrm{C}\right.$ below the perennial average indices) average daily temperatures against the background of medium and high humidity in June, followed by alternation of hot (with maximum air temperature up to $+36.7^{\circ} \mathrm{C}$ ) and cool (with a maximum air temperature of $+18.8 \ldots+22.7^{\circ} \mathrm{C}$ ) periods provoked anomalies of plant development and firstly affected the quality of fruits (Figure 8).

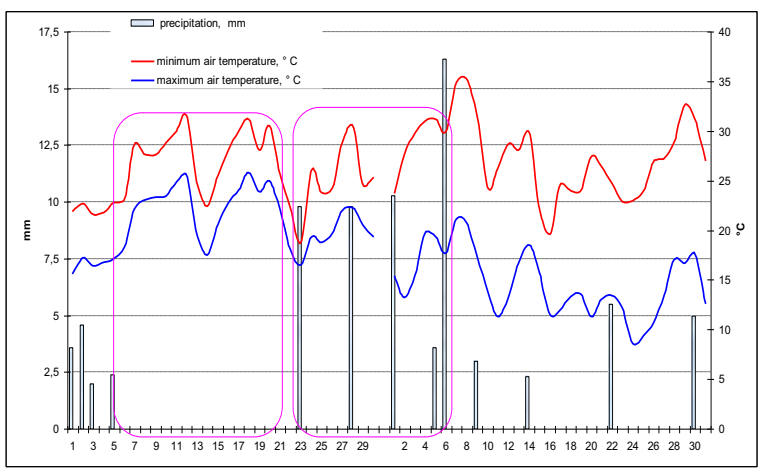

Fig. 7. Maximum and minimum air temperatures and precipitation in June-July 2020.

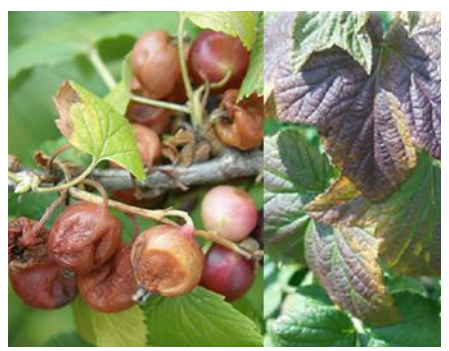

Fig. 8. Black currant plant reaction to weather anomalies of June-July. 
Abnormally high air temperatures and, most importantly, significant differences in day and night temperatures provoked burn damage to berries and anthocyanin leaf coloration (Figure 9).

Non-invasive contact monitoring of photosystem 2 reaction of Zelyonaya Dymka and Karmelita black currant varieties' leaves according to Fv/Fm indicator revealed inhibition of photosynthetic activity at the beginning of the second decade of May. Thus, in the third decade of April - the first decade of May, the values of Fv/Fm were 0.764 r.u. for Karmelita variety and 0.75 r.u. for Zelyonaya Dymka variety (at the theoretical maximum of this indicator 0.85 r.u.); in the second decade of May, the indicators decreased to the values of 0.618 r.u. for Karmelita variety and 0.622 r.u. for Zelyonaya Dymka variety, but further with improved weather conditions, photosynthetic leaf activity of both varieties recovered to values close to optimal.

It should be noted that despite the stronger response to weather anomalies, the photosynthetic activity of Karmelita variety leaves recovered faster than that of the Zelyonaya Dymka variety - i.e. the dynamic curve of the Fv/Fm indicator had more pronounced peaks (Figure 10). However, the average vegetational indicator of this variety's leaves' photosynthetic activity was slightly higher than that of Zelyonaya Dymka - 0.72 r.u. and 0.707 r.u. respectively.

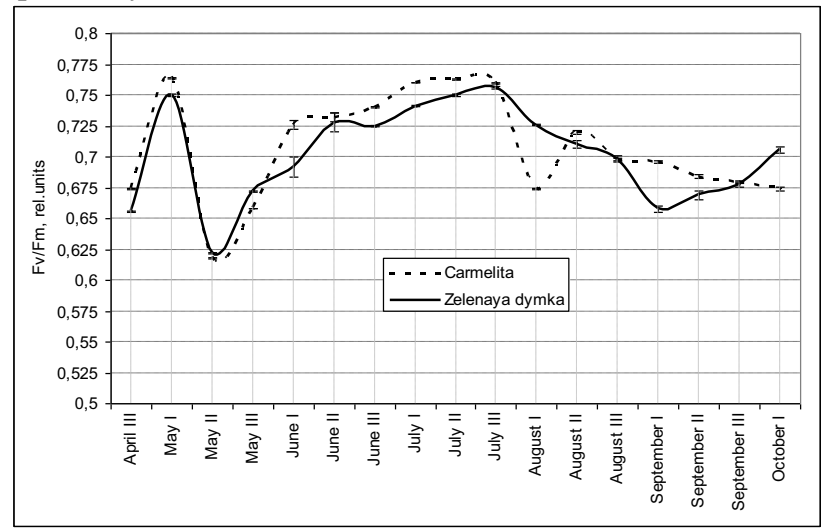

Fig. 9. Dynamics of photosynthetic activity of black currant leaves during the growing season 2020 depending on the variety.

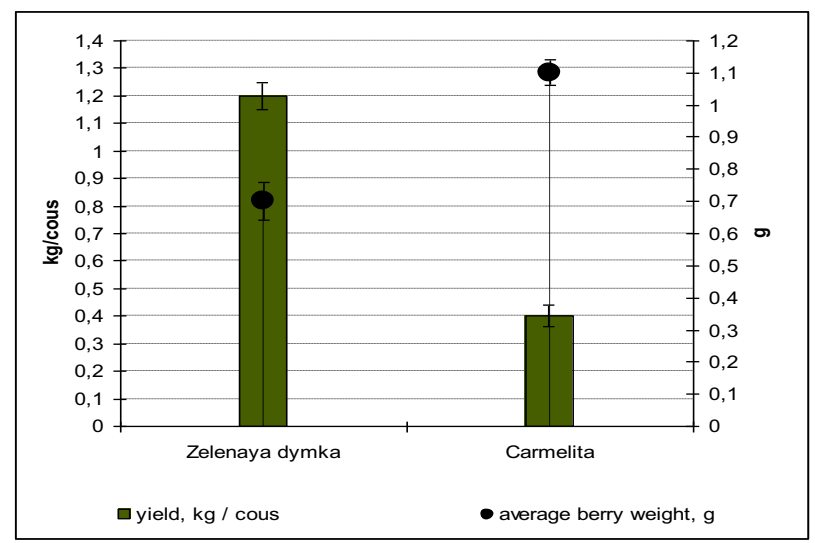

Fig. 10. Yield and average weight of berries of black currant varieties in 2020.

Yield analysis of studied black currant varieties showed that the above anomalies of the water-temperature regime of the vegetation period provoked its significant losses. The 
strongest influence was noted in Karmelita variety - the average yield was $0.4 \mathrm{~kg} / \mathrm{bush}$, which is $84 \%$ lower than the perennial average, while Zelyonaya Dymka variety's yield losses were less - no higher than $58 \%$ relative to the perennial average. However, it should be emphasized that Karmelita variety had an average weight of berries of $1.1 \mathrm{~g}$, whereas in Zelyonaya Dymka variety it did not exceed $0.7 \mathrm{~g}$ (Figure 11).

Comparative analysis of photosystem response depending on plant age showed that younger plants of both varieties respond more strongly to the effects of weather anomalies, dynamic peaks of the $\mathrm{Fv} / \mathrm{Fm}$ indicator is somewhat more pronounced especially in Karmelita variety, while the average varietal indicators of older plants are higher than those of younger ones. The highest average varietal indicator $\mathrm{Fv} / \mathrm{Fm}$ was noted in seven-year-old plants of Zelyonaya Dymka variety - 0.73 r.u., whereas in three to five-year-old plants of the same variety it did not exceed $0.7 \mathrm{r}$. u.

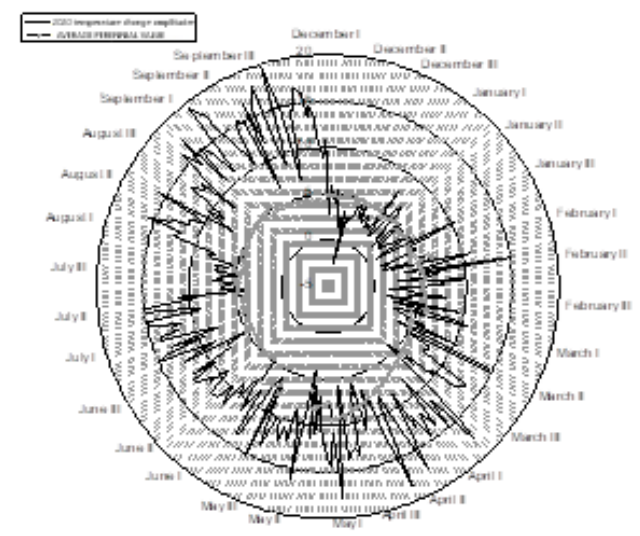

Fig. 11. Amplitude of daily air temperature difference in 2020 .

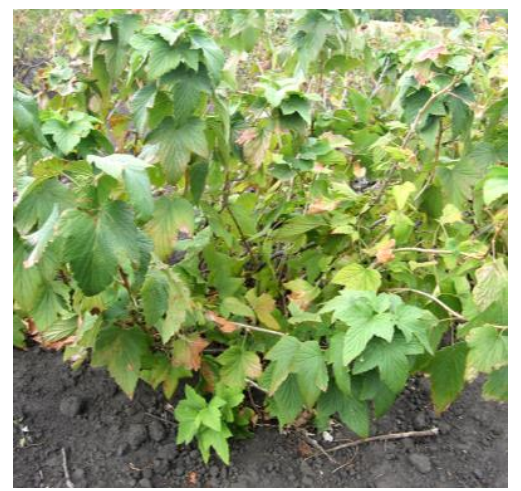

Fig. 12. Condition of Zelyonaya Dymka black currant plants in October 2020.

Therefore, in our opinion, young plants are more susceptible to the influence of watertemperature abnormalities, whereas functional systems of adult plants (over 5 years) have more formed protective mechanisms, thus tolerate the effects of temperature and humidity changes easier.

No less significant influence on black currant plants condition, their preparation for winter and the risk of possible winter damage was exerted by the water-temperature regime of August - October. The peculiarity of this period in 2020 was the alternation of hot (with air temperature up to $30^{\circ} \mathrm{C}$ ) and cool (up to $8.4^{\circ} \mathrm{C}$ ) periods, a large difference in daytime and night temperatures (up to $16^{\circ} \mathrm{C}$ ) and, most importantly, almost complete 
absence of precipitation at abnormally low (up to $23 \%$ ) humidity. In addition, the high amplitude of the daily air temperature difference was noted, which significantly exceeded the perennial average (Figure 12).

\section{Conclusion}

Thus, the main distinguishing feature of the entire 2020 growing season was a significant instability of the water-temperature regime - dry periods with high air temperatures were followed by wet and cool. Deviations of the water-temperature regime of the vegetation period 2020:

- abnormally high average daily temperatures in March at low air humidity;

- low average daily temperatures against the background of medium and high humidity in April - June;

- alternation of hot and cool periods in July-August;

- $\quad$ significant difference between night and daytime air temperatures.

- The most significant types of black currant plants reaction were noted during 2020 growing season:

- unstable dynamics of photosynthetic leaf activity during the entire vegetation period

- $\quad$ increase of the photosynthesis level in the third decade of September in Zelyonaya Dymka variety

- $\quad$ damage to buds by spring frosts

- $\quad$ sunburns and berries shedding in July

- decrease in the average berry weight and, as a result, the plantings' productivity

It was noted that early ripening variety Karmelita was more affected by spring frosts than mid-ripening Zelyonaya Dymka variety.

Analysis of the photosystem 2 reaction of studied black currant varieties' leaves showed that Karmelita variety was more labile - it showed more pronounced dynamic peaks of photosynthetic leaf activity at weather conditions change than that of Zelyonaya Dymka variety.

Comparative analysis of photosystem response depending on plant age showed that younger plants of both varieties respond more strongly to the effects of weather abnormalities, i.e., they are more susceptible to water-temperature regime abnormalities influence, whereas functional systems of adult plants (over 5 years) have more formed protective mechanisms.

\section{References}

1. F H, Wagner et al, Biogeosci, 13, 2537 (2016)

2. H. Hänninen, The Annual Cycle Under Changing Climatic Conditions, Boreal and Temperate Trees in a Changing Climate: Modelling the Ecophysiology of Seasonality. Springer, Netherlands, Dordrecht, 263 (2016)

3. M. Vanoni, H. Bugmann, M. Nötzli, C. Bigler, For. Ecol. Manag, 382, 51 (2016)

4. S. M. Matveev, Yu. G. Chendev, A. R. Lupo, J. A. Hubbart, D. A. Timashchuk. Pure Appl. Geophys, 174, 1427 (2017)

5. S. M. Matveev, A. Milenin, D. Timashuk, Journal of Forest Science, 64(10), 427 (2018)

6. V. V. Matskovsky, The climatic signal in the width of annual rings of coniferous trees in the north and in the center of the European territory of Russia, 148 (2013) 
7. E. M. Tsukanova, System for diagnosing the state of fruit plants. Express diagnostics of the functional state of plants and evaluation of the effectiveness of technology, 292 (2011)

8. T.V. Zhidyokhina, Modern trends in the sustainable development of berry growing in Russia: collection of scientific works. FSSI “I.V. Michurin FSC", 1, 61 (2018)

9. T.V. Zhidyokhina, Temperate horticulture for sustainable development and environment: ecological aspects. Waretown, NJ: Apple Academic Press, 309 (2018)

10. H. Kreuzwieser, H. Rennenberg, Molecular and physiological responses of trees to waterlogging stress Plant Cell Environ., 37 (2014)

11. B. Genty, J.M. Briantais, N.R. Baker, Biochimica et Biophysica Acta, 990, 87 (1989)

12. E. Tsukanova, E. Tkachev, Agro XXI, 10-12, 8 (2009)

13. Meteorological data archives 1931-2017 «Tsentral'no-Chernozemnoye UGMS» Tambov and Voronezh

14. T.P. Ogoltsova, E.P. Kuminov, Program and methodology for breeding fruit, berry and nut crops, 314 (1995)

15. Program and methodology for the study of varieties of fruit, berry and nut crops, under gen. ed. E.N. Sedov and T.P. Ogoltsova, 608 (1999)

16. Dale. Appl. Biol., 99(1), 99 (1981)

17. S. D. Knyazev, N.S. Levgerova, M.A. Makarkina, A.V. Pikunova, E.S. Salina, E.I. Chekalin, T.V. Yanchuk, M.A. Shavyrkin. Black currant breeding: methods, achievements, directions. Monograph, 328 (2016) 